\title{
Enantioselective Extraction of Racemic Amlodipine Using Tartaric Acid Derivatives and $\beta$-Cyclodextrin Derivatives as Chiral Selectors
}

\author{
Hairul Nazirah Abdul Halim*, Maizatul Akmam Ahmad, Azalina Mohamed Nasir, Muhammad \\ Syarhabil Ahmad, Akmal Hadi Ma'Radzi and Zulfakar Mokhtar
}

School of Bioprocess Engineering, Universiti Malaysia Perlis, Kompleks Pusat Pengajian Jejawi 3, 02600 Arau, Perlis,
Malaysia

\begin{abstract}
The distribution behavior of amlodipine enantiomers in a two-phase system containing tartaric acid derivatives in organic phase and beta-cyclodextrin $(\beta-C D)$ derivatives in aqueous phase has been studied. The effect of extraction equilibrium time, influence of different alkyl chains of tartaric acids, types of beta-cyclodextrin derivatives, organic solvents and buffer $\mathrm{pH}$ were investigated. It was found that hydroxypropyl- $\beta$-cyclodextrin (HP- $\beta$-CD) has the strongest recognition ability among three $\beta$-CD derivatives of HP- $\beta-\mathrm{CD}$, hydroxyethyl- $\beta$-cyclodextrin (HE- $\beta$-CD) and methylated$\beta$-cyclodextrin (Me- $\beta$-CD) while D-diisopropyl tartrate has the strongest ability among four tartaric acid derivatives of Ldiisopropyl tartrate, D-diisopropyl tartrate, L-diethyl tartrate and D-diethyl tartrate. The distribution coefficient and enantioselectivity, $\alpha$ gave an optimum value at $\mathrm{pH}$ 5.0.
\end{abstract}

Keywords: Chiral drug, Enantioselective extraction, Racemic amlodipine.

\section{INTRODUCTION}

Amlodipine, 3-ethyl 5-methyl-2-[(-2-(aminoethoxymethyl)-4-(2-chlorophenyl)-1,4-dihydro-6-methyl-3,5-pyridinedicarboxylate, is a racemic drug that belongs to the calcium channel blockers group, being used for treating hypertension and angina pectoris $[1,2]$. It acts as a calcium antagonist inhibiting the membrane influx of calcium ions in vascular smooth muscles and cardiac muscles which in turn affects their contractile process and results in reduced blood pressure [3].

Today many drugs are used as a racemic mixture. All enantiomers may have different effects on the pharmacological activity, metabolism process and toxicity on human body $[4,5]$. Like other chiral drugs, amlodipine consists of $(S)$-amlodipine and $(R)$-amlodipine. It has been reported that $(S)$-amlodipine shows a potent calcium channel blocker activity $[6,7]$ while the $(R)$-amlodipine has shown to release nitric oxide in the peripheral blood vessels which may lead to peripheral edema [8]. Hence, in order to reduce the incidence of peripheral edema and other side effects, it is beneficial to separate $(R)$-amlodipine from racemic $(R, S)$ amlodipine.

There are many techniques for separation of enantiomers such as crystallization, enzymatic conversion, chromatography and kinetic resolution [9]. These techniques are useful to separate the enantiomers of racemic drugs but there is still need for more efficient separation methods. Crystallization is the most used technique for separation of enantiomers but this technique requires many steps. Thus, it

*Address correspondence to this author at the School of Bioprocess Engineering, Universiti Malaysia Perlis, Kompleks Pusat Pengajian Jejawi 3, 02600 Arau, Perlis, Malaysia; Tel: +604-9798840; Fax: +604 9798755; E-mail: hairulnazirah@unimap.edu.my is time-consuming and cost-inefficient [9]. Enzymatic conversion is very expensive due to its single-action while chromatography is not suitable for production of large quantities of chiral substances. Solvent extraction is a good alternative method for chiral separation because it is usually preformed by dispersion of one immiscible phase in the other [10]. Moreover, it can be used in industrial scale which can be performed continuously with good effect and high recovery $[5,11]$.

The aim of the present study is to understand the distribution behavior of amlodipine enantiomers in a twophase system containing tartaric acid derivatives in organic phase and beta-cyclodextrin derivatives in aqueous phase. The parameter studied includes the effect of extraction equilibrium time, influence of different alkyl chain of tartaric acids, types of beta-cyclodextrin derivatives, organic solvents and buffer $\mathrm{pH}$.<smiles>CCOC(=O)C1=C(COCCN)NC(C)=C(C(=O)OC)[C@H]1c1ccccc1Cl</smiles>

Fig. (1). Structure of amlodipine.

\section{MATERIALS AND METHODS}

\subsection{Chemicals}

Racemic amlodipine was purchased from MTT Pharma in China (>98\%). $\beta$-CD derivatives and tartaric acid 
derivatives were obtained from Sigma Aldrich. Chemicals and solvents were purchased from Sigma Aldrich.

\subsection{Preparation of Aqueous and Organic Solutions}

An aqueous solution consist of $0.05 \mathrm{mmol} / \mathrm{L}(R, S)$ amlodipine and $0.10 \mathrm{~mol} / \mathrm{L} \quad \beta-\mathrm{CD}$ was prepared in 10 $\mathrm{mmol} / \mathrm{L}$ acetate buffer. The $\mathrm{pH}$ was adjusted to $\mathrm{pH}$ 5.0. An organic phase consist of $0.20 \mathrm{~mol} / \mathrm{L}$ tartaric acid derivatives which were dissolved in organic solvent.

\subsection{Extraction Procedure}

Batch extraction experiments were conducted by pipetting $3 \mathrm{ml}$ of aqueous solution containing $0.05 \mathrm{mmol} / \mathrm{L}$ of $(R, S)$-amlodipine and $0.1 \mathrm{~mol} / \mathrm{L} \beta-\mathrm{CD}$ with $3 \mathrm{ml}$ of the organic phase containing $0.20 \mathrm{~mol} / \mathrm{L}$ tartaric acid derivatives, into $100 \mathrm{ml}$ baffled flask. The flasks were then vigorously shaken in orbital shaker for the desired contact time to reach the maximum extract of $(R)$-amlodipine into the organic phase. The experiments were run at the temperature of $10^{\circ} \mathrm{C}$. The content of the flask was then transferred into a separatory funnel to separate the two phases. After the two phases were separated, the concentrations of $(R)$ and $(S)$ amlodipine in aqueous phase were measured by HPLC.

The distribution coefficients of $(R)$ and $(S)$-Amlodipine, $k_{R}$ and $k_{S}$ extracted from aqueous into organic phase were determined as Eq. (1) and Eq. (2);

$k_{R}=\frac{\text { Concentration of }(\mathrm{R}) \text {-Amlodipine in organic phase }}{\text { Concentration of }(\mathrm{R}) \text {-Amlodipine in aqueous phase }}$

$k_{S}=\frac{\text { Concentration of }(\mathrm{S}) \text {-Amlodipine in organic phase }}{\text { Concentration of }(\mathrm{S}) \text {-Amlodipine in aqueous phase }}$

The enantioselectivity $(\alpha)$ is defined as the ratio $\left(k_{R} / k_{S}\right)$ of both distribution coefficients of $(R)$-amlodipine to $(S)$ amlodipine in an aqueous-organic two-phase system containing chiral selector in each phase as Eq. (3);

$\alpha=\frac{k_{R}}{k_{S}}$

\subsection{Analytical Method}

The concentration of $(R)$ and $(S)$-amlodipine in aqueous phase was determined using a HPLC system (Shimadzu, Japan) equipped with a UV detector at the UV wavelength of $240 \mathrm{~nm}$. The standard curve was used to quantify the enantiomer. A $150 \mathrm{~mm}$ x $4.0 \mathrm{~mm}$ I.D. CHIRAL-AGP analytical column (ChromTech, Haegersten, Sweden) was used. The mobile phase was $10 \mathrm{mmol} / \mathrm{L}$ acetate buffer solutions ( $\mathrm{pH} 4.5)$ : 1-propanol $(99: 1, \mathrm{v} / \mathrm{v})$ at a flow of 0.9 $\mathrm{mL} / \mathrm{min}$. The $\mathrm{pH}$ of the aqueous phase was measured with a pH meter (Fisher Scientific, MA, USA).

\section{RESULTS AND DISCUSSION}

\subsection{Effect of Time of Chiral Extraction}

In order to investigate the equilibrium time of extraction, $0.05 \mathrm{mmol} / \mathrm{L}(R, S)$-amlodipine and $0.10 \mathrm{~mol} / \mathrm{L} \mathrm{HP}-\beta-\mathrm{CD}$ in $10 \mathrm{mmol} / \mathrm{L}$ acetate buffer $\mathrm{pH} 5.0$ were shaken in orbital shaker with $0.20 \mathrm{~mol} / \mathrm{L}$ D-diisopropyl tartrate in decanol as organic solvent for the desired contact time. It was found that the chiral extraction reaches equilibrium after 6 hours.

\subsection{Effect of Organic Solvents}

Table 1 shows the influence of different organic solvents on distribution coefficient, $k$ and enantioselectivity, $\alpha$ of amlodipine. The aqueous phase contains $0.05 \mathrm{mmol} / \mathrm{L}(R, S)$ amlodipine in $10 \mathrm{mmol} / \mathrm{L}$ acetate buffer and $0.10 \mathrm{~mol} / \mathrm{L} \mathrm{HP}$ $\beta$-CD. There is no chiral selector in organic phase. From the Table 1, we can see the extraction performance of the three different kinds of organic solvents, alcohol > alkyl halide > hexane, which might be related with the polarity and interaction of different organic solvents with solute. For alcohol group listed in Table 1, the enantioselectivity, $\alpha$ increased with the increase of the length of alcohol chain. It is seen from Table $\mathbf{1}$ that $n$-decanol is a suitable organic solvent for the extraction of racemic amlodipine.

Table 1. Effect of Organic Solvents on $k$ and $\alpha$

\begin{tabular}{|c|c|c|c|}
\hline Organic Solvents & $\boldsymbol{k}_{\boldsymbol{R}}$ & $\boldsymbol{k}_{S}$ & $\boldsymbol{\alpha}$ \\
\hline \hline$n$-pentanol & 3.56 & 3.65 & 0.98 \\
\hline$n$-hexanol & 0.97 & 0.94 & 1.04 \\
\hline$n$-heptanol & 0.53 & 0.50 & 1.05 \\
\hline$n$-octanol & 0.26 & 0.24 & 1.08 \\
\hline$n$-decanol & 0.42 & 0.28 & 1.47 \\
\hline 1,2 -dichloroethane & 0.10 & 0.11 & 0.94 \\
\hline Dichloromethane & 0.20 & 0.20 & 1.00 \\
\hline Hexane & 0.02 & 0.03 & 0.66 \\
\hline
\end{tabular}

\subsection{Effect of $\beta$-CD Derivatives}

A complex that formed between guest molecules and $\beta$ $\mathrm{CD}$ is depending on the size, shape and polarity of the guest molecule and various interactions involving electrostatic forces and hydrogen bonding. The size of the guest molecule determines whether it fits into the cavity, shape and polarity that influence the possible stabilizing effects by interactions within the cavity or with side groups on the cavity rim of $\beta$ CD [12]. The size of the guest molecule of amlodipine enantiomers fits into the cavity of $\beta-C D$ derivatives. Therefore, $\beta-C D$ derivatives can form complexes with amlodipine enantiomers. However the complexes that formed between amlodipine enantiomers and $\beta-C D$ derivatives depend on the polarity of $\beta-\mathrm{CD}$ derivatives. So, three of the $\beta$-CD derivatives may show different enantioselectivities toward amlodipine enantiomers.

Table 2 shows that HP- $\beta-C D$ has a higher distribution coefficient and high enantioselectivity as compared to HE- $\beta$ $\mathrm{CD}$ and Me- $\beta-\mathrm{CD}$. The finding was similar to Mikus et al., 2009 which studied the separation of amlodipine enantiomers using capillary electrophoresis [13]. It is also found from Table 2 that the value of $k_{S}$ is less than $k_{R}$. It indicates that three $\beta-C D$ derivatives recognize $S$ enantiomer, which means that $\beta-C D$ forms complexes with $(S)$-amlodipine and is retained in the aqueous phase. HP- $\beta$ $\mathrm{CD}$ is chosen to be the most suitable chiral selector in aqueous phase among these three $\beta$-CDs derivatives. 
Table 2. Effect of $\beta$-CD Derivatives

\begin{tabular}{|c|c|c|c|}
\hline Types of $\boldsymbol{\beta}$-CD & $\boldsymbol{k}_{\boldsymbol{S}}$ & $\boldsymbol{k}_{\boldsymbol{R}}$ & $\boldsymbol{\alpha}$ \\
\hline \hline HP- $\beta-C D$ & 0.28 & 0.74 & 2.62 \\
\hline HE- $\beta$-CD & 0.24 & 0.28 & 1.17 \\
\hline Me- $\beta-C D$ & 0.26 & 0.37 & 1.44 \\
\hline
\end{tabular}

\subsection{Effect of Tartaric Acid Derivatives}

The distribution coefficient and enantioselectivity of amlodipine enantiomer were also determined in chiral extraction containing $0.10 \mathrm{~mol} / \mathrm{L} \mathrm{HP}-\beta-\mathrm{CD}$ in aqueous phase and $0.20 \mathrm{~mol} / \mathrm{L}$ tartaric acid derivatives in organic phase.

Table 3. Effect of Tartaric Acid Derivatives

\begin{tabular}{|c|c|c|c|}
\hline Types of tartaric acid & $\boldsymbol{k}_{\boldsymbol{S}}$ & $\boldsymbol{k}_{\boldsymbol{R}}$ & $\boldsymbol{\alpha}$ \\
\hline \hline L-diisopropyl & 0.55 & 0.59 & 1.09 \\
\hline D-diisopropyl & 2.61 & 3.00 & 1.15 \\
\hline L-diethyl & 0.72 & 0.81 & 1.12 \\
\hline D-diethyl & 0.93 & 1.06 & 1.13 \\
\hline
\end{tabular}

Table 3 shows that the distribution coefficient of $k_{S}$ and $k_{R}$ increased when tartaric acid derivatives were added as a chiral selector in organic phase. The value of $k_{R}$ for D-tartaric acid derivatives is larger than the value of $k_{R}$ for L-tartaric acid derivatives. This indicates that D-tartaric acid derivatives preferentially recognize $(R)$-enantiomer. Table 3 shows that enantioselectivity of extraction increases with the addition of length alkyl chain of D-tartrate. Hence, the Ddiisopropyl tartrate was chosen as the chiral selector in the organic phase because it has a high enantioselectivity among them.

\subsection{Effect of Buffer pH}

The $\mathrm{pH}$ is an important factor for consideration in the separation of enantiomers as it impacts the states of amlodipine enantiomers. The distribution coefficient and enantioselectivity of amlodipine enantiomers were studied with $0.20 \mathrm{~mol} / \mathrm{L}$ D-diisopropyl tartrate in decanol solvent and $0.10 \mathrm{~mol} / \mathrm{L} \mathrm{HP}-\beta-\mathrm{CD}$ in $10 \mathrm{mmol} / \mathrm{L}$ acetate buffer at different $\mathrm{pH}$ values.

Amlodipine has one distinct group which can be protonated to give an increase and decrease of $\mathrm{pH}$, which is the amine group (Fig. 1). In aqueous solution, amlodipine exists in two states of neutral molecule and anion. Therefore, there exists influence of $\mathrm{pH}$ on the distribution behavior of amlodipine enantiomers in enantioselective extraction. From the Fig. (2), the values of $k_{S}$ decrease with the rise of $\mathrm{pH}$

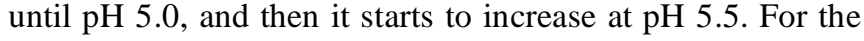
values of $k_{R}$, it increases with the rise of $\mathrm{pH}$ but it decrease at pH 6.0.

From the Fig. (3), the enantioselectivity increases with the increase of $\mathrm{pH}$ until it reaches at $\mathrm{pH} 5.0$ and then it starts to decrease. The possible reasons may be that the ratio between protonated and unprotonated amlodipine decreases with the rise of $\mathrm{pH}$ value. HP- $\beta$-CD and D-diisopropyl tartrate mainly have chiral recognition ability and affinity for molecular amlodipine but not for ionic amlodipine. Ionic amlodipine only exists in aqueous phase. At pH 5.0, the enantiomers of amlodipine are expected to be unprotonated. So, pH 5.0 was an appropriate choice in view of the bigger enantioselectivity of the enantioselective extraction.

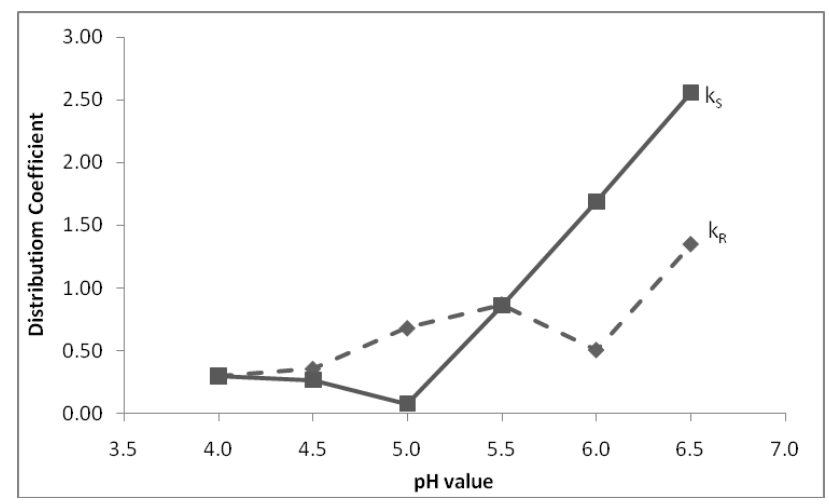

Fig. (2). Influence of $\mathrm{pH}$ on distribution coefficient, $k_{S}$ and $k_{R}$. Organic phase: [D-diisopropyl tartrate] $=0.10 \mathrm{~mol} / \mathrm{L}$ and $[\mathrm{HP}-\beta$ $\mathrm{CD}]=0.20 \mathrm{~mol} / \mathrm{L}$.

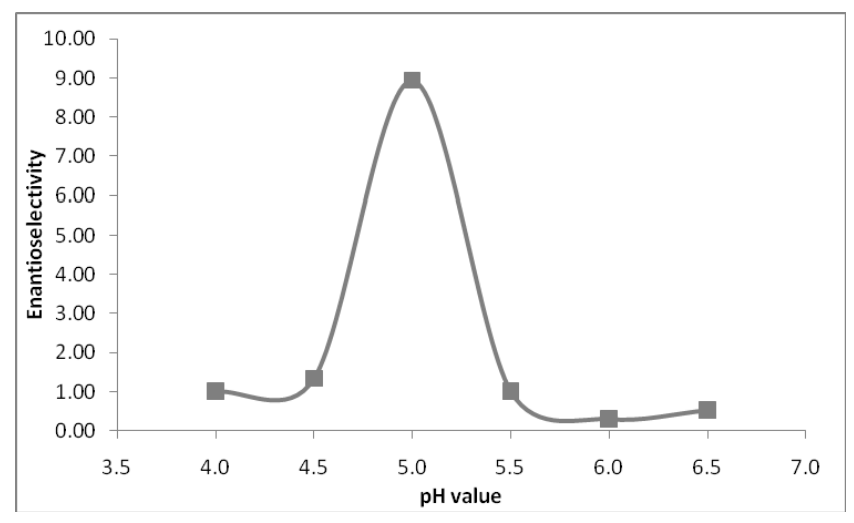

Fig. (3). Influence of $\mathrm{pH}$ on enantioselectivity. Organic phase: [Ddiisopropyl tartrate $]=0.10 \mathrm{~mol} / \mathrm{L}$ and $[\mathrm{HP}-\beta-\mathrm{CD}]=0.20 \mathrm{~mol} / \mathrm{L}$.

\section{CONCLUSION}

The present work has investigated the enantioselective extraction of racemic amlodipine using tartaric acid derivatives in organic phase and $\beta-C D$ derivatives in aqueous phase as the chiral selectors. It was found that HP- $\beta-C D$ has the strongest recognition ability among three $\beta-C D$ derivatives of HP- $\beta-\mathrm{CD}, \mathrm{HE}-\beta-\mathrm{CD}$ and Me- $\beta-\mathrm{CD}$ while Ddiisopropyl tartrate has the strongest ability among four tartaric acid derivatives of L-diisopropyl tartrate, Ddiisopropyl tartrate, L-diethyl tartrate and D-diethyl tartrate. The enantioselectivity was optimum at pH 5.0.

\section{ACKNOWLEDGEMENT}

The authors acknowledge the financial support by the National Science Fund by Minister of Science, Technology and Innovation of Malaysia through the project number 0301-15-SF118. 


\section{REFERENCES}

[1] Yang, Q.; Chung, T.-S. Modification of the commercial carrier in supported liquid membrane system to enhance lactic acid flux and to separate 1,d-lactic acid enantiomers. J. Membr. Sci., 2007, 294, $127-131$

[2] Zhong, N.; Zhao, X.; Ma, H. Chen Method for the enantiomeric separation of optical active amlodipine. US 2007/0093661 A1, April 26, 2007.

[3] Johansen, S. S.; Genner, J. A fatal case of amlodipine poisoning. $J$. Clin. Forensic Med., 2003, 10, 169-172.

[4] McConathy, J.; Owens, M. J. Stereochemistry in Drug Action. $J$. Clin. Psyhiatry, 2003, 5, 70-73.

[5] Tang, K.; Song, L.; Liu, Y.; Pan, Y.; Jiang, X. Separation og flurbiprofen enantiomers by biphasic recognition chiral etraction. Chem. Eng. J., 2010, 158, 411-417.

[6] Chung, Y. S.; Ha, M. C. Process for the preparation of (S)-(-)amlodipine. US 2007/0155969 A1, July 5, 2007.

[7] Rohini, R. J.; Ramesh, A. J.; Mukund, K. G. A process for the preparation of S-(-)-amlodipine salts. EP 1407773 A1, April 14, 2004.
Zhang, X. P.; Loke, K. E.; Mital, S.; Chahwala, S.; Hintze, T. H. Paradoxical Release of Nitric Oxide by an L-Type Calcium Channel Antagonist, the $\mathrm{R}+$ Enantiomer of Amlodipine. $J$. Cardiovasc. Pharmcol., 2002, 39, 208.

[9] Jiao, F. P.; Chen, X. Q.; Yang, L.; Hu, Y. H. Enantioselective extraction of mandelic acid enantiomers using ester alcohol Ltartarate as chiral selector. Latin Am. Appl. Res., 2008, 38, 249-252.

[10] Viegas, R. M. C.; Afonso, C. A. M.; Crespo, J. G.; Coelhoso, I. M. Modelling of the enantio-selective extraction of propanolol in a biphasic system. Sep. Purif. Technol., 2007, 53, 224-234.

[11] Schuur, B.; Winkelman, J. G. M.; Heeres, H. J. Equilibrium studies on enantioselective liquid-liquid amino acid extraction using a cinchona alkaloid extractant. Ind. Eng. Chem. Res., 2008, 47, 10027-10033.

[12] Valle, E. M. M. D. Cyclodextrins and their uses: A review. Proc. Biochem., 2004, 39, 1033-1046.

[13] MikuŠ, P.; Maráková, K.; Valášková, I.; Havránek, E. Determination of amlodipine enantiomers in pharmaceuticals using capillary electrophoresis separation and diode array detection. Pharmazie, 2009, 64, 76-79.

(C) Halim et al.; Licensee Bentham Open.

This is an open access article licensed under the terms of the Creative Commons Attribution Non-Commercial License (http://creativecommons.org/licenses/by-nc/3.0/) which permits unrestricted, non-commercial use, distribution and reproduction in any medium, provided the work is properly cited. 